\title{
Gesto Furtivo
}

\section{Lilian Soares}

Artista e professora Adjunta no Departamento de Comunicação Visual Design da Escola de Belas Artes da UFRJ.

Contato: liliancsoares@eba.ufrj.br

\section{RESUMO}

$\mathrm{O}$ artigo fez parte da tese Horizonte Indelével, pesquisa em que a escrita e suas fábulas se confundem com a materialidade da prática artística. Neste artigo-ensaio procura-se iniciar uma reflexão sobre o ato de desenhar e seu gesto, tendo como pano de fundo a linguagem das obras de Cy Twombly e o filme "Cave of forgotten dreams" de Werner Herzg. Autores como Badiou, Barthes, Blanchot são interlocutores nesta escrita.

Palavras-chave: gesto, desenhar, Cy Twombly, Werner Herzog

\section{ABSTRACT}

The article was part of the thesis Indelible Horizon, a research in which writing, and its fables are confused with the materiality of artistic practice. This article-essay seeks to initiate a reflection on the act of drawing and its gesture, having as a background the language of the works of Cy Twombly and the film "Cave of forgotten dreams" by Werner Herzg. Authors such as Badiou, Barthes, Blanchot are interlocutors in this writing.

Keywords: gesture, drawing, Cy Twombly, Werner Herzog 
Há aqui neste espaço um risco. Há aqui um traço. Há este ato que do gesto precisa para ser. Esta linha que se movimenta e se contorce não pode ser apenas isto que o vestígio evidencia. A linha é o acometimento de algo que nada pretende, apenas é. Desenhar carrega este tempo de linha febril, de uma convulsão que brota e logo em seguida se esvai. "Há também o desenho no qual você marca ou altera uma superfície, estabelecendo com ele um vínculo corporal: o gesto, o arco da mão, o dedo, o osso" (MEIRELLES, p.197, 2009).

O corpo sente, vibra, se agarra as linhas, ao instante. Talvez haja no gesto algo que se desvencilha e passa a caminhar só, sem rumo: um desenhar cartografando. Desenhar já carrega em si esta busca por um vestígio de um espaço fora. Há este diálogo entre o suporte e a inscrição, entre o corpo e esta ação. Neste sistema o artista encontra-se diante do suporte. Encontra-se diante de uma palidez desencontrada. Eis, então, o ato, este desenhar simplesmente. Não há precisão. Há apenas isto que permanece, sistematicamente se formando sobre o papel.

No instante em que a inscrição assume presença e imagem expressiva, algo se desvanecesse. Ao mesmo tempo em que o traço em seu acúmulo vai ocupando o suporte, esta inscrição parte deste, que no final do ato, desaparece: a superfície. Talvez isso tudo seja um diálogo, uma troca. A inscrição não pode existir sem a superfície que o acolhe e este ao acolhê-la se desfaz. Sobre isto Richard Serra disse: "o desenho é uma maneira pela qual eu levo adiante um monólogo interior com o ato de fazer no momento exato em que é feito" (SERRA, p.50, 2014).

Badiou em seu texto "Drawings" (2015) faz uma reflexão, a partir do poema "Description without Place" de Wallace Stevens, sobre a arte e o desenho contemporâneo. A partir desta poesia, Badiou aponta para a particularidade da arte contemporânea como uma descrição sem lugar. Em suas divagações ele entende que, de certa maneira, há uma sucessão de desaparecimentos, fuga do gesto, da imagem; das vozes que fazem, por exemplo, a performance, descrever, a partir de açóes com o corpo, um espaço que fala fora de si mesmo. Já o desenho se mostra como um complexo de marcas que não possuem lugar. As marcas, os traços, as linhas que compóem os emaranhados de um desenho não estão fechados, dominados ou encobertos pelo suporte. Ao contrário, as linhas, os traços, as marcas criam com e apesar do suporte um espaço aberto. O corpo e o desenho deslocam o lugar e criam um lugar inexistente. $\mathrm{O}$ que se vê é um lugar que não se descreve. O que se vê é um quase-lugar, um espaço em que o ser esvanece para o aparecer disto que é o próprio desenho. Traços e linhas permitem o nascer de um lugar sem lugar, de uma superfície vazia, mas imbuída de espaço vacante.

O filósofo ainda afirma que esta característica inerente ao desenho-arte de ser uma descrição sem lugar - ou diríamos, por meio de um olhar menos literal da palavra 'description', representação sem lugar — possui uma relação com a antiga questão filosófica de ser e aparecer ou, ainda, parecer ser e parecer aparecendo em um lugar. E, de maneira equivalente: existir e não existir. Nesse sentido, esta é, também, uma questáo pertinente ao ato de desenhar. $\mathrm{O}$ papel, o suporte, existem por si mesmos, "como uma totalidade fechada", diria Badiou. Contudo, a marca (ou a linha) não existe por ela mesma. Ela depende deste suporte e precisa compor alguma coisa neste dentro, nesta superfície. O papel enquanto plano de 
fundo não existe, pois ele é, antes de tudo, um espaço aberto criado pela marca. Ele tem todas as formas, todos os caminhos, todas as inscriçóes. Logo, há uma relação de reciprocidade entre existir e desaparecer que constituí a essência do desenho. A partir desta concepção, Badiou comenta que no desenhar a indagação existencial do Hamlet é na realidade outra: ser e não ser, existir e desaparecer. É neste ponto que a força da fragilidade do desenho se evidencia, pois a linha e a superfície não existem simplesmente, não é apenas uma questão de ser ou não ser, mas tem em sua essência o paradoxo do existir e do desaparecer.

O artista observa, segue a linha por caminhos desconexos. Perde-se neste espaço que se faz presente. Esta percepção é força motora de um movimento criador que nunca cessa. E, com isso, o ato se repete por diversas vezes por essa vontade de continuar a seguir desvendando este mistério que se instala.

O gesto do desenhar, de produzir o vestígio, a marca torna a superfície espaço fértil para a (des)construção. A evidência do vestígio se intercala entre este ato de buscar uma representação de um lugar e de se perder neste lugar do nenhum. Repete-se o percurso da linha que se comprime, se expande, se parte, se conecta, pulsa. $\mathrm{O}$ vestígio busca um lugar que nunca chega. Não há fidelidade com a superfície. A superfície, tomada pela linha, torna-se percurso e espaço. Ser caminho, ser espaço, ser linha e ser superfície constituem e engendram o ato criador que desaparece para se tornar um emaranhado do desenho. O que resta ao artista é o desejo de persistir neste caminhar na superfície porosa e densa das linhas.

As linhas assumem diferentes formas e, cada uma delas, ao se formar se desfaz. O que resta é apenas o índice de coisa alguma. Talvez ao percorrer traços estejamos nos aproximando da escrita, de certa cartografia indicial. A linha está sempre no entre estados e percursos. A marca, o vestígio não são representação de lugar. Elas são um estado de incompletude, de indiscernibilidade. Desenhar tem natureza ampla, extensa, longínqua. A amplidão desta prática se descola do ato para se mostrar como traço fragmentário do gesto, em uma incompletude de linhas que ora se afastam, se aproximam, ora se sobrepóem.

"The pure Drawing is the material visibility of invisibility." ${ }^{1} \mathrm{O}$ desenho constitui-se como índice da invisibilidade. $\mathrm{O}$ gesto da inscrição no mesmo instante que se revela, desaparece. E a linha, na fugacidade de seu fenômeno, se mostra inalcançável. O todo escapa no ato. A linha se ausenta de si mesma, se esvazia de toda sua representatividade e mecanicidade, de todo o estado de inscrição, para permitir que este lugar se construa no e com seu desfazimento. Há na ação uma experiência que é partida e chegada, revelar e apagar.

Viver o acontecimento da linha transpassa o desenhar. A reflexão sobre o gesto desenhante aproxima-se das discussóes que Roland Barthes (2014) desenvolve a respeito da obra de Cy Twombly. Há um aspecto na obra deste artista que foi logo apontado por Barthes: a relaçáo do gesto com a escritura. Esta não é de imitação, mas apenas de um gesto alusivo a ação de escrever. Trata-se de uma fronteira constantemente amolecida no ato criador entre o desenhar e o escrever.

O gesto é uma espécie de negligência disforme, de rabisco que corre, escorre e segue. O que está retido, diz Barthes (2014) na escritura de Cy Twombly, é o gesto, não o resultado dele. A cosmicidade presente no trabalho de Cy Twombly é constante na poética do desenho-escritura. No texto, Barthes (2014) comenta a maneira como pinturas de Twombly permi- 
tiram o desvencilhamento entre o olho e a mão, pois suas imagens são febris movimentos, um convite para apreciar o vestígio inflamável do gesto.

A forma imperativa do ato desenhante de Twombly é táo impactante quanto a simplicidade de suas marcas. Sua ação está constantemente impulsionada por uma repetição do movimento, revelada a partir do vestígio que, com isso, se destaca do ato, adquirindo certa autonomia. As linhas de suas obras não pedem para ver, mas para re-ver, rever. $\mathrm{O}$ ato da escrita requer este caráter manual, este trajeto da mão para que a partir disto as formas das letras sejam definidas, mas nas obras do artista isso não se concretiza. A mão que conduz o traço na escrita parece aqui seguir um caminho particular: "isto cai, isto chove finamente, isto deita-se como as ervas, isto rasura por fastio, como se se tratasse de tornar visível o tempo, a tremura do tempo" (BARTHES, 2014, p.165).

A repetição do gesto nos faz retomar a reflexão do existir e desaparecer pontuada por Badiou. A inscrição sistemática das obras de Twombly pouco a pouco vai sendo apagada para se tornar um fundo disforme. $\mathrm{O}$ que antes se inicia como ato torna-se experiência de um desfazimento da superfície para a construçáo de um espaço outro, em um provável jogo entre o corpo que se movimenta e uma forma que vai invadindo, recriando um lugar. Estes traços que a superfície absorve fala ao corpo sobre sua negação, desconstrução, sua risível perenidade.

Ascende à superfície a materialidade do risco, no entanto, um corpo se engendra de maneira liberta, sem organização, um corpo que é linha, corpo-linha, corpo-traço. $\mathrm{O}$ escritor, no ato da escritura, morre para fazer erigir um Eu próprio da palavra, aponta Blanchot (2011). O artista ao desenhar carrega esta mesma potência de não mais existir, de desaparecer. Há apenas um corpo imbuído de rastro, linhas e pontos; de um ser, ele mesmo, o próprio gesto. E, ao mesmo tempo, de maneira quase desconexa, o gesto se destaca do corpo, em uma espécie de arbitrariedade do espírito, para invadir e (des)construir o espaço. Isto ocorre, talvez, não pelo peso da aparência das linhas, ou por uma imposição motora, mas a partir de uma distração atenta no instante mesmo em que se pousa a ponta do instrumento sobre a matéria. A essência, o ser das coisas, disto que se corporifica, está na leveza do ato, do sentir de um estado de sonhar vigilante (BACHELARD, 2010).

Entre ato e gesto tornamo-nos um ser em contato com outros universos transcendentes, um "ser decantado" (HILST, 2004, p.19), nos impulsionando a romper as barreiras entre o mundo real e um mundo poético. Neste encontro-confronto as superfícies nos acolhem e nos negam. $\mathrm{O}$ desenhar nos provoca um estado de "homem poético" como fala Herzog (2011).

Poderíamos dizer que a narrativa de "Cave of Forgotten Dreams" faz um paralelo a estas discussôes. No filme, Herzog (2011) trata de pinturas rupestres na caverna francesa de Chauvet. O diretor desconstrói a narrativa distanciada e afirmativa que os personagens - cientistas, pesquisadores, historiadores - estabelecem sobre os desenhos paleolíticos. $\mathrm{O}$ diretor transforma os desenhos em um encontro constante com a origem, como se defronte deles, ele, Herzog (2011), estivesse diante de inscrições indecifráveis. E, com um olhar avessador, busca desvendar os mistérios que tais desenhos tentam evidenciar, mas acaba por se envolver em um estado de sonho, em um diálogo com os grafismos rupestres em estado de aparição e desaparição.

Os desenhos tangenciam a um devir-animal (DELEUZE, 2005), de um ser que se encontra em outra natureza, em 
uma redefiniçao e reconstrução do espaço, do território. Nos gestos operantes, o homem no ato criador torna-se este ser outro. O que se acomete nas superfícies da caverna parece ser uma intensa troca e conflito entre o ato, o gesto e a superfície. Diante das linhas que estão sempre no porvir, o ser, este "homem poético", batalha e se metamorfoseia no ato criador. E, assim, o diretor revê o olhar objetivo dos cientistas e evidencia que a única certeza dos vestígios é seu vir a ser — sua potência — onde as narrativas tornam-se camadas de gestos criadores.

A abordagem acerca dos desenhos rupestres adotada por Herzog (2011) se aproxima do trabalho de Cy Twombly. Ambos parecem acometidos por um estado poético do desenhar e do desenho. Os trabalhos de Twombly apresentam formas que transitam entre uma caligrafia e uma figuração, em uma espécie de grafismo indecifrável, de uma escrita que nasce do diálogo com o suporte. O gesto furtivo, de um grafismo displicente compóe uma espécie de amalgama do corpo do artista com o suporte, do ato com o gesto, da linha com a superfície. Cy Twombly em certa medida vive este devir animal, que os paleolíticos viveram na caverna Chauvet. Herzog (2011) com sua câmera se metamorfoseia neste ser quase-paleolítico, neste homem-desenhante, que está em estado constante de devir. Este homem paleolítico não é um ser particularizado, náo procura no desenhar sobre as paredes da caverna imitar o animal, ou tornar o animal em outra coisa, ele é o próprio animal sem sê-lo; é com seus traçados um bloco de devir.

Há no ato de desenhar este "entre dois" como propóe Deleuze (2011), entre pontos, entre linhas - o corpo e a superfície, a linha e o espaço, o corpo e o vestígio - criam esta espécie de zona de indiscernibilidade, de vizinhança, de um devir-outro. Assim, o artista, no ato do desenhar, deixa de ser mais um individuo, para ser matéria atemporal, deste outro que é linha, traço, gesto, ato.

Com trabalhos que vão da caligrafia a figuração, $\mathrm{Cy}$ Twombly, em um traçar desajeitado e displicente, produz desenhos como se escrevesse com a mão esquerda, tornando seu grafismo por vezes ilegível e indecifrável. Nesta prática artística há um pêndulo que varia entre uma forma de meditação gestual, impondo uma repetição quase constante das desformas. E, este caminhar em vestígios, nos leva a máxima dita por Barthes (2014, p.179): "Cy Twombly desconstrói a escrita”. Esta desconstrução parte do traço impaciente, firme e rápido que compóe as imagens. O desenhar está nesta zona em que a escritura se corporifica em outra forma, se aproximando e se distanciando da caligrafia. Este ato, tomado ou náo por certa rasura, presentifica o ato da escritura.

$\mathrm{Na}$ solidão do desenhar o acontecimento do gesto-ato antecede o artista, ele está constituído, assim, como a escrita literária, de uma manifestação da "fala neutra", de um sussurro incompreensível que exige do artista uma única ação possível: desenhar. Diante da superfície, diante disto que lhe resta e que nasce no entre, na fronteira do instante entre o desenhar e o escrever, todo traço articulado na superfície tenta incansavelmente dar corpo ao inominável, ao indecifrável. "O poeta é aquele que ouve uma linguagem sem entendimento" (BLANCHOT, p.47, 2011). Talvez esteja nessa frase do Blanchot um outro caminho para abordar a experiência desenhante.

\section{Notas de fim:}

1. Tradução livre: "O desenho puro é o material visível do invisível” (Badiou, 2015). 


\section{Referências Bibliográficas}

BACHERLARD, Gaston. A Intuição do Instante. Campinas: Verus Ed., 2010.

BADIOU, Alain. Drawing. Disponível em: <http://lacan. com/symptom12/?p=65>. Acesso em agosto de 2015

BARTHES, Roland. Oóbvio e o obtuso. Lisboa: Ediçōes 70, 2014

BLANCHOT, Maurice. A conversa infinita 1: a palavra plural. São Paulo: Escuta, 2010.

O espaço literário. Rio de Janeiro: Rocco, 2011.

DELEUZE, Gilles. O abecedário de Gilles Deleuze. Disponível em: <http://stoa.usp.br/prodsubjeduc/files/262/1015/Abecedario+G.+Deleuze.pdf>. Acessado em 20 de agosto de 2015.

Conversaçōes. São Paulo: Ed.34, 1992

HERZOG, Werner. A Caverna dos Sonhos Esquecidos. 2011

HILST, HILDA. Do desejo. São Paulo: Globo, 2004

MEIRELES, Cildo. Cildo Meireles. Rio de Janeiro: Beco do Azougue, 2009.

SERRA, Richard. Richard Serra: escritos e entrevistas, 1967-2013. São Paulo: IMS, 2014. 